\title{
Några skattefrågor
}

Author(s): D. Davidson

Source: Ekonomisk Tidskrift, Årg. 9 (1907), pp. 305-314

Published by: Wiley on behalf of The Scandinavian Journal of Economics

Stable URL: http://www.jstor.org/stable/3436790

Accessed: 11-06-2016 07:40 UTC

Your use of the JSTOR archive indicates your acceptance of the Terms \& Conditions of Use, available at

http://about.jstor.org/terms

JSTOR is a not-for-profit service that helps scholars, researchers, and students discover, use, and build upon a wide range of content in a trusted digital archive. We use information technology and tools to increase productivity and facilitate new forms of scholarship. For more information about JSTOR, please contact support@jstor.org.

The Scandinavian Journal of Economics, Wiley are collaborating with JSTOR to digitize, preserve and extend access to Ekonomisk Tidskrift 


\section{Några skattefrågor.}

\section{Ett förbiseende i afseende å fastighetsbeskattningen vid den senaste skattereformen.}

Som bekant hade i Kungl. Maj:ts proposition vid senaste riksdag rörande allmänna bevillningen endast med afseende å inkomstbevillningen föreslagits, att skatteobjektet skulle utgöras af nästföregående års inkomst; i afseende å fastighetsbevillningen bibehölls däremot hittills gällande regel, så att föremålet för fastighetsbevillningen enligt detta förslag fortfarande skulle vara fastighets afkastning under det löpande året. Riksdagen ansåg sig emellertid ej kunna godkänna detta förslag, utan beslöt, att den för inkomstbevillningen föreslagna regeln äfven skulle utsträckas till fastighetsbevillningen. I följd häraf stadgar den af detta ărs riksdag antagna bevillningsförordningen dels i $3 \S$, att fast egendom skall uppskattas till det värde egendomen haft nästföregående år, dels i 2 , att bevillning för fast egendom skall erläggas af den, som för nästföregående år författningsenligt mantalsskrifvits eller bort mantalskrifvas săsom ägare (resp. innehafvare) af fastigheten. Den, som förvärfvar en fastighet under loppet af år 1908, skall sålunda först I9IO påföras bevillning för fastigheten; I909 skall bevillningen påföras den, som för 1908 var mantalsskrifven för fastigheten, och detta var ju säljaren. Det kan sålunda hända, att $\mathrm{i}$ det närmaste 2 ăr förflyta, innan köparen af en fastighet blir påförd fastighetsbevillning för densamma.

Vid införandet i kommunallagarna af de ändringar, som betingades af ändringarna af bevillningsförordningen, förbisågs emellertid, att den af Riksdagen $i$ afseende $\stackrel{\circ}{a}$ fastighetsbevillningen vidtagna ändringen kräfde en motsvarande ändring af kommunallagarnas bestämmelser rörande den kommunala skattskyldigheten för fast egendom. Om vi frånse från de fall, då på landet brukare af jord skall påföras kommunal skatt för. jorden, gäller såväl för land som för stad, att den, som äger fastigheten, då den kommunala debiteringen sker, är kommunalt skattskyldig för fastigheten.' I $57 \S$ af förordningen angående kommunalstyrelse på landet heter det, att skatt- 
skyldig »är en hvar, som inom kommunen äger - — - fastighet», och i $57 \S$ af förordningen rörande stad stadgas, att »medlem af stadskommun är i allmänhet skyldig - _ - lämna bidrag i förhållande till sammanlagda beloppet af den bevillning till staten, som enligt näst förut upprättade, vederbörligen fastställda bevillningstaxeringslängd skall erläggas för honom tillhörig fast egendom eller blifvit honom påförd för inkomst af kapital eller arbete». Det är sålunda icke den, som blifvit påförd fastighetsbevillning för en fastighet, som ovillkorligen skall erlägga kommunalskatt för samma fastighet. Detta anges med tillräcklig tydlighet både för land och stad, men det är särskildt pointeradt $i$ afseende å stad. Under det att det $\mathrm{i}$ afseende $̊$ inkomst af kapital eller arbete heter, att en persons kommunala skattskyldighet är bestämd i proportion till den bevillning, som blifvit personen i fråga själf påförd för inkomst af kapital och arbete, säges det $\mathrm{i}$ afseende $\mathrm{a}$ fastighet, att kommunalskatten skall beräknas efter den bevillning, som skall erläggas för den skattskyldige tillhörig fastighet; att bevillningen för fastigheten skall vara den kommunalt skattskyldige påförd, fordras ej. Dessa bestämmelser ha med hittills gällande föreskrifter rörande bevillningen medfört, att om A under ăr 1907 säljer en fastighet till $\mathrm{B}$, så skall för nämnda år bevillningen för fastigheten påföras $\mathrm{A}$, men kommunalutskylderna åter påföras $\mathrm{B}$. Hvad man än kan säga om denna anordning, så innebär den ej năgon orimlighet. (Före I889 gällde, hvad stad beträffar, att kommunalutskylder för fastighet alltid skulle erläggas af den, som påförts bevillning för fastigheten. ${ }^{1}$ Men denna anordning ansågs innebära väsentliga oegentligheter, hvarför den ersattes med den nu gällande).

Det är emellertid lätt att se, att denna nu gällande regel för den kommunala skattskyldigheten för fastighet ej är förenlig med de nya bestämmelserna angående fastighetsbevillningen. Om $t$. ex. en person under år 1908 förvärfvar en fastighet, skall, såsom redan nämnts, fastighetsbevillningen år 1909 påföras säljaren, så att köparen först 1910 kommer att påföras bevillning för fastigheten $i$ fråga. Men enligt bestämmelserna om den kommunala skattskyldigheten skulle köparen af fastigheten redan år 1908 påföras kommunalutskylder för den köpta fastigheten. D. v. s.

157 lydde nämligen för stad sålunda: smedlem af en stadskommun är i allmänhet skyldig att till de utgifter, som för kommunens gemensamma behof böra enligt $S \mathbf{S}$ 3 mom. uttaxeras, lämna bidrag i förhållande till den sammanlagda bevillning till staten för fast egendom eller för inkomst af kapital eller arbete, som - - - blifvit honom påförd i näst förut upprättade, vederbörligen fastställda bevillningstaxeringslängd.s 
sedan köparen år 1908 påförts kommunalskatt för fastigheten, påföres säljaren år 1909 bevillning för fastigheten.

Anledningen till detta fel ligger däri, att vederbörande förbisett att, sedan Riksdagen beslutat att föremålet för fastighetsbevillningen skulle utgöra näst föregående års af kastning af fastigheten, den nödvändiga konsekvensen däraf blifvit, att äfven föremålet för den kommunala beskattningen af fastighet bör utgöras af nästföregående års afkastning af fastig. heten. Men däraf följer, att den kommunala skattskyldigheten för fastighet bör falla på den, som ägt fastigheten under nästföregående år, men ej på den, som äger fastigheten under det löpande året. Detta $\mathrm{i}$ full analogi med hvad som enligt den nyantagna bevillningsförordningen gäller för industriell näring; år 1908 träffar den kommunala skatten för inkomst af näring den, som under 1907 utöfvat näringen, ej den, som under 1908 utöfvar densamma. I full analogi härmed bör år 1908 den kommunala skatten för fastighet träffa den, som under år 1907 innehaft fastigheten, men ej den, som först 1908 förvärfvar fastigheten.

För det år, då fastighet ombyter ägare, uppstår en svårighet, på grund af att endast en person făr uppföras såsom skattskyldig för fast egendom för ett och samma år. För närvarande gälla i detta fall, såsom sagts, olika principer för bevillning och för kommunalskatt, i det bevillning påföres den, som äger fastigheten vid årets ingång, kommunalskatt åter den, som äger fastigheten, då den kommunala debiteringen sker, d. v. s. vid årets slut. Med tillämpning af samma regler borde alltså bestämmelsen rörande den kommunala skattskyldigheten för fastighet affattas så, att denna skyldighet åligger den, som vid nästföregående års slut ägt fastigheten. ${ }^{1}$

En annan utväg vore att låta den kommunala skattskyldigheten för fastighet, liksom fallet är i afseende å inkomst, först inträda, sedan skyldighet att erlägga bevillning inträdt. Hvad stad beträffar, skulle man sålunda $\mathrm{i}$ hufvudsak återgå till den lydelse $57 \S$ ägde före ändringen den 8 mars 1889. Lydelsen skulle alltså bli ungefär denna: »Medlem af en stadskommun är i allmänhet skyldig att till de utgifter, som för kommunens gemensamma behof böra enligt $\S 5$ mom. 3 uttaxeras, lämna bidrag i förhållande till sammanlagda beloppet af den bevillning till staten, som enligt näst förut upprättade, vederbörligen fastställda bevillningstaxeringslängd blifvit honom påförd för fastighet eller för inkomst af kapital eller

1 Såsom jag redan nämnt, har jag i det föregående lämnat å sido de fall, då brukare af fastighet pà landet skall erlägga kommunalskatten för fastighet. 
arbete». Men en dylik bestämmelse skulle leda till att synnerligen lång tid komme att förflyta efter en fastighets förvärfvande, innan den kommunala skyldigheten för fastigheten öfverflyttades på den nye ägaren. Om en person förvärfvar en fastighet under år 1908, skulle han enligt nu ifrågavarande alternativ först i slutet af år ı10 påföras kommunalutskylder för fastigheten. Denna utväg är af detta skäl ej lämplig. Därtill kommer, att den är oförenlig med bestämmelsen att för utarrenderad fastighet på landet brukaren skall påföras kommunal skatt.

Hvilken utväg man än väljer, så blir det alltid nödvändigt att företaga ändringar på andra områden af den kommunala lagstiftningen. Så t. ex. måste bestämmelsen om inträdande af rösträtt för fastighet ändras.

I det föregående har jag endast tagit hänsyn till den lydelse kommunallagarna för närvarande äga. Som bekant har vid senaste riksdag eventuellt, nämligen under förutsättning att de hvilande förslagen till ändring af den politiska rösträtten blifva definitivt antagna, beslutats vissa ändringar i kommunallagarna. Men äfven om dessa ändringar gäller, att de ej undanröjt det fel, hvaraf nu gällande bestämmelser lida. En revision af förstnämnda ändringar är sålunda ock af nöden.

\section{Om beskattning af "vinst" genom försäljning af rätt att teckna aktier.}

Något i högsta instansen behandladt mål rörande denna fråga har åtminstone icke publicerats. Upsala läns pröfningsnämnd hade förra året att behandla denna fråga. En skattskyldig hade bland sina inkomster upptagit ett belopp, utgörande vinst genom försäljning af aktieteckningsrätt. Bevillningsberedningen ansåg emellertid denna s. k. vinst ej vara beskattningsbar inkomst. Pröfningsnämnden åter var af motsatt mening och inräknade densamma i den beskattningsbara inkomsten. Då särskildt i denna aktieemissionernas tid försäljning af aktieteckningsrätt ofta förekommer, är det ju af särskildt intresse att klargöra, om köpeskillingen för dylik rätt bör betraktas såsom beskattningsbar inkomst.

Härvid är det emellertid nödvändigt att närmare precisera frågan. Det finnes ju fall, där det är alldeles otvifvelaktigt, att vinst af här ifråga- 
varande slag skall beskattas. T. ex. om en person köper aktieteckningsrätt i syfte att sälja densamma med vinst och sedermera också företar denna försäljning, så är naturligtvis vinsten å denna spekulationsaffär beskattningsbar inkomst. Men samma gäller ju, om man gör en spekulationsaffär, som har redan emitterade aktier till föremål. Hvad frågan egentligen gäller är, huruvida köpeskillingen för såld aktieteckningsrätt alltid är beskattningsbar inkomst, sålunda äfven om icke någon spekulationsaffär af nyssangifna slag föreligger. Jag antager följande fall: en person har under en följd af år innehaft aktier i ett bolag, hvilka aktier ostridigt förvärfvats i syfte att placera kapital. Bolaget ifråga besluter emittera nya aktier, och nyssomnämnda person säljer den honom tillkommande rätten att teckna nya aktier i bolaget. I detta fall kunde genom försäljningen af de gamla aktierna icke någon beskattningsbar inkomst uppkomma. Och frågan gäller, huruvida under denna förutsättning köpeskillingen för den försålda teckningsrätten är att betrakta såsom beskattningsbar inkomst.

Den ståndpunkt, som Upsala läns pröfningsnämnd intog i nyss omnämnda fall och som innebar, att äfven under nu angifna förutsättning vinsten å teckningsrättens försäljning bör betraktas såsom beskattningsbar inkomst, skulle kunna försvaras på följande sätt.

Försäljning af aktieteckningsrätt är i sak detsamma, som om man tecknar nya aktier i syfte att sälja dem med vinst och sedermera äfven försäljer dem. Denna senare transaktion innebär ju ett förvärf af aktier i syfte att med vinst försälja dem, och differensen mellan försäljningspriset och teckningspriset (med afdrag af eventuella kostnader) skulle utgöra den beskattningsbara vinsten å denna affär. Då en försäljning af aktieteckningsrätt blott är en förkortning af nu nämnda transaktion, bör den i beskattningshänseende behandlas efter samma grunder och sålunda köpeskillingen för den försålda aktieteckningsrätten betraktas såsom beskattningsbar inkomst.

Emot denna argumentering är först och främst att invända, att köpeskillingen för aktieteckningsrätt $\mathrm{i}$ många fall icke alls är någon vinst $\mathrm{i}$ egentlig mening, $i$ det genom nyteckningen af aktier de gamla aktieägarne förlora lika mycket, som köpeskillingen för aktieteckningsrätten utgör. $T$. ex. i ett bolag med ett aktiekapital af I million kronor och andra fonder, uppgående till samma belopp, betinga aktierna, som nominellt lyda på $\mathrm{I}, 000$ kronor, ett pris af 2,000 kronor. Bolaget emitterar nu I,000 nya aktier till ett teckningspris af $\mathrm{I}, 000$ kronor. För att emissionen skulle ha skett till ett pris, som med hänsyn till bolagets fonder motsvarade de nya aktiernas verkliga värde, skulle teckningspriset bort sättas till circa 1,500 
kronor. Ty före emissionen motsvarades hvarje aktie af $1, \infty 00$ kronor $\mathrm{i}$ grundfond och I,000 kronor i andra fonder, men efter den nya emissionen har sistnämnda belopp sjunkit till 500 kronor. I detta fall medför försäljning af aktieteckningsrätt $i$ allmänhet ej någon verklig vinst. Teckningsrätten bör i detta fall betinga ett pris af c:a 500 kronor, men med samma belopp minskas genom den nya emissionen värdet af gammal aktie.

Det skulle visserligen kunna invändas, att detta förhållande - att teckningsrättens försäljning $i$ förevarande fall ej medför någon verklig vinst för denna rätts innehafvare - ej är något bindande skäl för att köpeskillingen för försåld teckningsrätt icke bör beskattas såsom inkomst. Om t. ex. ett aktiebolag, som samlat stora dispositionsfonder och hvars aktier i följd däraf stigit i pris, beslutar utdela dessa fonder, och i följd däraf aktiernas gällande värde sjunker med ett belopp motsvarande utdelningen, så skall ändock denna utdelning betraktas såsom beskattningsbar inkomst för aktieägarne. Ja hela denna anordning med emission af aktier till underpris kan sägas $i$ sak innebära detsamma som en utdelning af fonder. I det ofvan anförda exemplet skulle samma resultat kunnat vinnas på följande sätt. Bolaget utdelar först af samlade fonder 500 kronor pr aktie och emitterar sedan nya aktier till ett teckningspris af $\mathrm{I}, 500$ kronor. Resultatet blir i detta fall detsamma som i förra exemplet, ty ägare af gammal aktie erhåller 500 kronor, och sådan aktie sjunker i värde från $2, \infty 00$ till I,500 kronor; förvärfvet af ny aktie kostar I,500 kronor. $\mathrm{Nu}$ är det ju otvifvelaktigt, att de gamla aktieägarne måste inräkna denna utdelning å 500 kronor pr aktie i deras beskattningsbara inkomster, fastän denna utdelning icke medför för aktieägarne någon ekonomisk fördel. Och då borde ju äfven den, som försäljer teckningsrätt till aktier, som emitterats till underpris, blifva skattskyldig för vinsten å denna transaktion.

Să plausibel denna invändning än vid första påseende kan synas, håller den emellertid ej stånd för en närmare kritik. Förhållandet är nämligen det, att enligt gällande bestämmelser själfva den formella utdelningsakten är afgörande för frågan, om en ekonomisk fördel, som tillfaller aktieägarne $\mathrm{i}$ ett aktiebolag, skall betraktas såsom beskattningsbar inkomst för dessa aktieägare. Nu är det tydligt, att om ett aktiebolag gör en större vinst, åtnjuta aktieägarne $\mathrm{i}$ och med detsamma den ekonomiska fördelen af denna vinst, sålunda äfven om vinsten icke utdelas utan reserveras. Och genom försäljning af aktierna kan denna ekonomiska fördel realiseras i penningar. När sedermera utdelningen af dessa reserverade medel sker, 
vinna aktieägarne icke någon ekonomisk fördel. Men aktieägarne beskattas för denna ekonomiska fördel, ej redan då de i sak komma i åtnjutande af densamma, utan först då den formella utdelningen sker. Häraf följer, att det nyssanförda resonnemanget är falskt. Den omständigheten - att emission af nya aktier till underpris med åtföljande försäljning af teckningsrätten till de nya aktierna medför samma resultat, som om aktiebolaget först utdelat en del af bolagets fonder och sedermera emitterat de nya aktierna till ett pris motsvarande deras verkliga värde - är sålunda ej något afgörande skäl för att köpeskillingen för teckningsrätt skall betraktas såsom beskattningsbar inkomst, ty annars skulle vinst å försäljning af aktier kunna beskattas såsom inkomst, äfven om aktierna ej inköpts i spekulationssyfte.

Aktieteckningsrätt kan betinga ett pris äfven i bolag utan samlade fonder, så $\mathrm{i}$ bolag, hvars rörelse drifves med hög vinst och kan utvidgas med bibehållande af samma relativa höjd hos vinsten. Om aktierna i ett dylikt bolag, som nominellt lyda på 1,000 kronor, på grund af rörelsens vinstgifvande beskaffenhet gälla 2,000 kronor, så böra, under de antagna förutsättningarna, äfven de nyemitterade aktierna komma att ha samma värde. Emitteras nu de nya aktierna till $\mathrm{I}, 000$ kronor med teckningsrätt för de gamla aktieägarne, så skörda dessa ju en positiv vinst af 1,000 kronor för hvarje rätt att teckna ny aktie. Här föreligger en verklig vinst, och det här ofvan angifna skälet mot en beskattning af köpeskillingen för teckningsrätten förefinnes sålunda icke.

Emellertid bör icke häller i detta fall priset för teckningsrätten betraktas såsom beskattningsbar inkomst. Om ägaren af en gammal aktie säljer denna i förening med teckningsrätten, så lär väl ingen ifrågasätta, att någon del af köpeskillingen för aktien borde betraktas såsom beskattningsbar inkomst. Men i så fall vore det ju inkonsekvent att beskatta köpeskillingen för teckningsrätten, när denna säljes särskildt för sig.

Det finnes emellertid ett för alla fall gällande skäl emot beskattning af s. k. vinst å försåld aktieteckningsrätt. Om en person säljer en rörelse, som han drifvit, så anses vinsten å denna försäljning ej vara beskattningsbar inkomst. Samma gäller naturligtvis, om han säljer en andel af rörelsen. Att sälja teckningsrätt till aktier är detsamma som att sälja andel i ett företag eller rörelse. Likviden för aktieteckningsrätt bör således ej beskattas săsom inkomst. Utan betydelse är det härvidlag på hvad grund teckningsrätten till aktier förvärfvas. Om t. ex. innehafvaren af en rörelse skänker rörelsen till en annan person och denne sedermera säljer 
rörelsen med vinst, blir denna vinst ej beskattningsbar inkomst. Och af samma skäl blir köpeskilling för aktieteckningsrätt ej beskattningsbar inkomst, äfven om teckningsrätten tilldelas för bolaget helt främmande personer eller förbehålles endast en del af aktieägarne i bolaget.

\section{Trustbildning och inkomstskatt.}

Att de i sockerförädlingen intresserade lyckats komma till enighet $\mathrm{i}$ afseende å sammanslutningen till en trust, är naturligt en händelse af mycket stort intresse. Dess betydelse i olika riktningar har i pressen diskuterats, och därvid har äfven berörts denna trustbildnings betydelse för inkomstskatten. Det har sålunda uppgifvits, att ett medverkande motiv till sockertrustens bildande skulle varit den besparing af inkomstskatt, som skulle åvägabringas genom det sätt, hvarpå trusten skulle organiseras. Trustens aktiekapital skulle sättas så högt, att trustens årsvinst ej komme att utgöra mycket mer än 6 procent af aktiekapitalet. I följd häraf skulle trusten såsom sådan slippa ifrån så godt som all inkomstskatt, under det att de aktiebolag, som skola ingå i trusten, för närvarande erlägga betydande belopp i inkomstskatt.

Jag lämnar här åsido frågan, om denna skattebesparing under några förhållanden kan spela någon större rol för sockertrusten; den gäller ju blott inkomstskatt, ej bevillning och kommunalskatt, hvilka senare ju äro oberoende af aktiekapitalets storlek. Det är vidare tydligt, att manipulationer af angifna art kunna ske äfven utan sammanhang med en trustbildning. Hvarje sockerbruksaktiebolag för sig kunde ha förverkligat det nämnda önskningsmålet: det hade blott behöft bildas ett nytt aktiebolag med ett aktiekapital af erforderlig höjd, hvilket inköpt det gamla sockerbruksaktiebolagets rörelse och ägodelar för högt pris. Detta förhållande minskar emellertid ej, utan är tvärtom ägnadt att öka intresset af frågan, om och i hvad mån det verkligen med nu gällande lagstiftning är möjligt att på detta sätt undandraga staten inkomstskatt.

En trust kan, som bekant, bildas på flera sätt. När trusten bildas af förutvarande aktiebolag, är det egentligen två sätt, som för vårt land kunna vara af något praktiskt intresse. Det ena sättet är, att trusten uppköper de särskilda aktiebolagens rörelse och ägodelar, hvarefter dessa bolag likvidera och upplösas. Det andra sättet är, att de särskilda aktiebolagen formaliter fortbestå och att trusten inskränker sig till att uppköpa akțierna $\mathrm{i}$ de särskilda bolagen eller åtminstone majoriteten af aktierna 
inom hvarje bolag. Enligt meddelande i pressen skulle sockertrusten ha valt den förra formen, men jag skall äfven undersöka, huru frågan bör besvaras för det fall, att det sistnämnda sättet för trustbildning användes.

Jag börjar med det första sättet för trustbildning, eller att trusten uppköper de särskilda företagens rörelse och ägodelar till höga priser. Emot besparingen af inkomstskatt för trusten i följd af trustens relativt höga aktiekapital stå följande skattetillägg. Trusten har att erlägga lagfartsstämpel $I_{2}$ proc. af värdet af de fastigheter, som trusten inköper. De särskilda aktiebolagen skola visserligen ej erlägga någon skatt för den vinst, de göra på rörelsens försäljning till trusten, men aktieägarne i dessa bolag, hvilka ju măste likvidera, få erlägga inkomstskatt för en del af de medel, som vid bolagens likvidationer till dem utdelas. Men för huru stor del däraf skatt skall erläggas, därom äro meningarna delade. Denna fråga måste, på grund af det sätt hvarpå sockertrusten bildats, nu få sin lösning. Och lämpligt vore, att vederbörande tillsåge, att alla hithörande fall komme under högsta instansens pröfning.

Bodin och Palmgren (se Själfdeklaration 4:de uppl. sid. I05) hylla den åsikten, att aktieägarne vid aktiebolagets likvidation skola erlägga inkomstskatt för hela den summa, som utöfver aktiernas nominella belopp utdelas till aktieägarne. ${ }^{1}$ Godkännes denna uppfattning, reduceras vinsten af skatteminskningen för trusten betydligt. Någon vinst kvarstår dock alltid, på grund af att skattefoten för trusten, ifall öfverkapitalisering ej ägt rum, skulle utgjort 4 proc., under det att skattefoten för delägarne i de särskilda sockerbruksaktiebolagen väl är betydligt mindre, kanske i medeltal knappast 2 proc. Därtill kommer visserligen äfven hänsyn till lagfartsstämpeln, men dess belopp är dock omöjligt att utan speciellt material ens relativt uppskatta.

Enligt den uppfattning, jag i denna tidskrift årg. 1903, sid. 361 o. ff., 440, 528 förfäktat, skulle trustens intressenter vinna sitt syfte med trustens öfverkapitalisering i betydligt större grad. Nämnda uppfattning utgår ifrån att aktieägarne ej äro skattskyldiga för annan utdelning än den, som tages ur medel, som $\mathrm{i}$ aktiebolagets hand varit beskattningsbar inkomst. $\mathrm{Nu}$ är det tydligt, att den vinst, som ett sockerbruksaktiebolag gör på försäljningen af sin rörelse till trusten, ej är för bolaget beskattningsbar inkomst, och enligt min uppfattning borde utdelning af denna vinst ej heller vara beskattningsbar inkomst för aktieägarne.

${ }^{1}$ De göra blott eventuellt undantag för det fall, att några eller alla bolagets delägare å sina aktier inbetalt mer än aktiernas nominella belopp. 
Jag vill ej här upprepa de skäl, som jag på nyss angifna ställen anfört för min uppfattning. Jag medger, att den af Bodin och Palmgren förfäktade åsikten i tillämpningen är mycket enklare än min. Men detta är ju ej något säkert kriterium på dess riktighet. Af vikt är emellertid, att frågan blir någon gång definitivt afgjord och helst $\mathrm{i}$ form af lagstiftning.

Om trusten bildas så, att trusten uppköper aktierna i de bolag, som skola sammanslutas, medför trustens öfverkapitalisering ingen minskning af inkomstskatten $\mathrm{i}$ jämförelse med förhållandena före trustens bildande. Ty då ju de gamla bolagen fortfarande bestå oförändrade, blir deras beskattning också oförändrad. Genom öfverkapitaliseringen af trusten vinnes emellertid, att trusten såsom sådan undgår inkomstskatt, hvaraf den annars skulle ha drabbats och som för intressenterne i trusten skulle inneburit en ökning af beskattning i jämförelse med förhållandena före trustens tillkomst.

D. Davidson. 